\title{
Synchronous fluorescence spectra of dissolved organic matter (DOM) of algal origin in marine coastal waters
}

\author{
Giovanni M. Ferrari ${ }^{1, *}$, Marina Mingazzini $^{2}$ \\ ${ }^{1}$ Institute for Remote Sensing Application, J.R.C., I-21020 Ispra (Va), Italy \\ ${ }^{2}$ Water Research Institute, C.N.R., I-20047 Brugherio (Mi), Italy
}

\begin{abstract}
Naturally occurring dissolved organic matter (DOM) was investigated in a lagoonal system with the aim to study the origin and mixing of the DOM components. Water samples were collected in the Sacca di Goro lagoon (Po river delta, Italy) and analysed by means of different techniques, such as fluorescence, absorption and dissolved orgamc carbon (DOC) measurements. Synchronous fluorescence spectra obtained from both laboratory algal cultures and benthic macroalgae collected in situ were compared with spectra from field samples in order to distinguish DOM components having autochthonous (algal) origin with respect to remote formation. Two main components could be identifjed on the basis of their synchronous fluorescent bands. The results indicated that the first band (band $\mathrm{hA}$ at $\lambda=275 \mathrm{~nm}$, prevailing in seawater samples, could reflect a recent biological production, while the second (bands $\mathrm{hB}$ and $\mathrm{hC}$ at $\lambda>300 \mathrm{~nm}$ ) prevailing in the tributaries water samples, could likely be due to older or remote formation. The synchronous peak height ratio hA:hB is proposed as an useful parameter describing the different contribution and mixing of the DOM components present in the lagoonal-estuarine waters.
\end{abstract}

KEY WORDS: DOM · Synchronus spectra $\cdot$ Lagoonal systems

\section{INTRODUCTION}

Dissolved organic matter (DOM) is a large contributor to the pool of organic matter in seawater and thus plays an important role in the global carbon cycle (Cauwet 1978, Mopper \& Degens 1979). In recent years dissolved organic carbon (DOC) has assumed more and more importance in the development of models for primary production estimation (Jackson 1993). Relationships between DOC and the optical properties of DOM, such as fluorescence and absorption, were studied to investigate the potential use of these optical methods to estimate DOC concentration (Stewart \& Wetzel 1980, 1981). The interaction of visible light with DOM (e.g. the parameter absorption) in water will be exploited by the new sensors as part of the Remote Sensing technique to assess DOM concen-

•E-mail address: massimo.ferrari@jrc.it tration in large areas both in the coastal region and in the open sea (Mueller \& Austin 1995). High sensitivity fluorescence spectroscopy has proven to be an effective tool to characterise and study the complex chemical composition of DOM in seawater (Coble et al. 1990, 1993, Mopper \& Schultz 1993). Synchronous fluorescence spectroscopy, applied to DOM studies, allows the isolation of the components present in natural aquatic media and thus can be useful to infer their origin. Russo (1985) suggested use of this method to identify structural parts of DOM, while Cabaniss \& Shuman (1987) recommended its use for 'fingerprinting' of different water masses considering fluorescence as a natural tracer.

Results of other studies, reported by Mopper \& Schultz (1993), indicate that marine DOM can be distinguished in 2 categories based on their different chemical behaviour during the DOC analysis: a more labile $\left(D O C_{\text {lab }}\right)$ and a more resistant $\left(D O C_{\text {res }}\right)$. $D O C_{\text {res }}$ is the difference in DOC concentration analysed using 
the high temperature combustion oxidation (HTCO) method (Sugimura \& Suzuki 1988) and that analysed with conventional chemical or photochemical oxidation method ('wet' technique). The DOC resistant fraction, the chemical composition of which is not known, appears relatively young and bio-reactive. It is made up of high molecular weight protein-like compounds, colloids and sub-micron particles of recent biological origin easily available for microbial uptake. $\mathrm{DOC}_{\text {res }}$ is present in the euphotic layer and can reach $60 \%$ or more of the total DOC. The second DOM fraction $\left(\mathrm{DOC}_{\mathrm{lab}}\right)$ is oxidable using the conventional oxidative photochemical/chemical procedure for the DOC analysis. $\mathrm{DOC}_{\text {lab }}$ is dominantly composed of humictype material, and it is present especially in deep waters, where it represents a major portion (30 to $80 \%$ ) of the total DOC concentration.

Although only a small part of DOM produced by phytoplankton has fluorescence properties (Momzikoff 1969, Duursma 1974), these are easily detectable by means of fluorescence spectroscopy. Traganza (1969) reported emission fluorescence spectra obtained analysing DOM produced by a rich bloom of Trichodesmium sp. in the Sargasso Sea in August 1967. Fogg (1966) found that between 7 to $50 \%$ of the carbon fixed in the euphotic zone of the water column was released in extracellular form. Apart from their possible intrinsic fluorescence properties, the extracellular products can represent the main precursors of the fluorescent matter produced in situ (Kalle 1963, Harvey et al. 1983). Sieburth \& Jensen (1969), investigating the chemical nature of algal substances in the sea, working specifically with Ascophyllum nodosum, demonstrated that algae excrete simple phenols which, in a slightly alkaline seawater medium, are slowly transformed into polyphenols which take part, along with proteinaceous and carboydrate matter, in further condensation reactions leading to complex structures which make up a considerable part of blue fluorescing DOM (gelbstoff or humic matter). In DOM of algal origin, a multitude of compounds have been found: carbohydrates, amino acids, peptides, proteins, organic acids, lipids, etc. (Hellebust 1974, Fogg 1983, Jensen 1984). The algal release of DOM mainly occurs during the stationary growth phase (Guillard \& Wangersky 1958, Marker 1965), where it represents $58 \%$ of total photosynthesis production, compared to $10 \%$ during the exponential growth phase (Myklestad et al. 1989).

The aim of the present work was to study DOM from natural water samples as well as from algal cultures. Water samples, collected in the Sacca di Goro lagoon as well as from rivers and channels belonging to the deltaic system of the Po river (Italy), were analysed for DOM by means of different techniques such as fluorescence, absorption and DOC measurements. Syn- chronous fluorescence spectroscopy was used to analyse the algal extracellular DOM and to verify how changes in extracellular production during the algal growth could be reflected in the spectral fluorescence features. Synchronous spectra from laboratory algal cultures were compared with DOM spectra from natural water samples in order to identify DOM components which could reflect an autochthonus (algal) origin with respect to remote (terrestrial, industrial, agricultural or urban) allocthonous formation.

\section{MATERIALS AND METHODS}

Test site and sampling. The test site, Sacca di Goro, is an environment which has been much studied and monitored with the aim of of protecting and optimising the local shell fish industry. The Sacca di Goro is a lagoon with a limited opening toward the sea but with a large fresh water input from the Po di Volano and from irrigation channels which transport a considerable amount of organic substances and nutrients into the lagoon. Thus, the fresh water inputs control the ecology of the lagoon. The optimal equilibrium conditions of maximum productivity are determined by several environmental factors: solar irradiation, temperature, nutrients, wind force, etc. When this delicate equilibrium fails, micro- and macroalgal blooms can occur, followed by decomposition which creates anoxia and results in the death of the shellfish and consequent economic loss. For this reason recent studies have concentrated on improving the understanding of the causes of the frequent equilibrium alterations. Presently, little is known about the ecological role of the DOM, formed in situ or transported by the rivers into the lagoon.

Water samples were immediately filtered after collection on prerinsed cellulose Millipore $0.22 \mu \mathrm{m}$ pore size membrane and stored in ambered glass bottles. An inhibitor of aerobic bacterial growth $[0.1 \mathrm{ml}$ of $10 \mathrm{mg} \mathrm{l}^{-1} \mathrm{NaN}_{3}$ (sodium azide)] was added to the samples, which were stored in a dark environment at $4^{\circ} \mathrm{C}$. The measurements, described below, were performed within a time interval in accordance with guidelines set down after test storage results as described by Ferrari (1990). A map of the Sacca di Goro showing the sample stations is given in Fig. 1.

Algal cultures. Both laboratory algal cultures and benthic macroalgal species collected in situ were analysed to characterise the extracellular DOM by fluorescence spectral analysis. The diatoms Skeletonema costatum, Nitzschia closterium, Phaeodactylum tricornutum, and the dinoflagellate Gymnodinium sp. were cultured and allowed to age over long periods of time under controlled conditions, as described by Mingazz- 


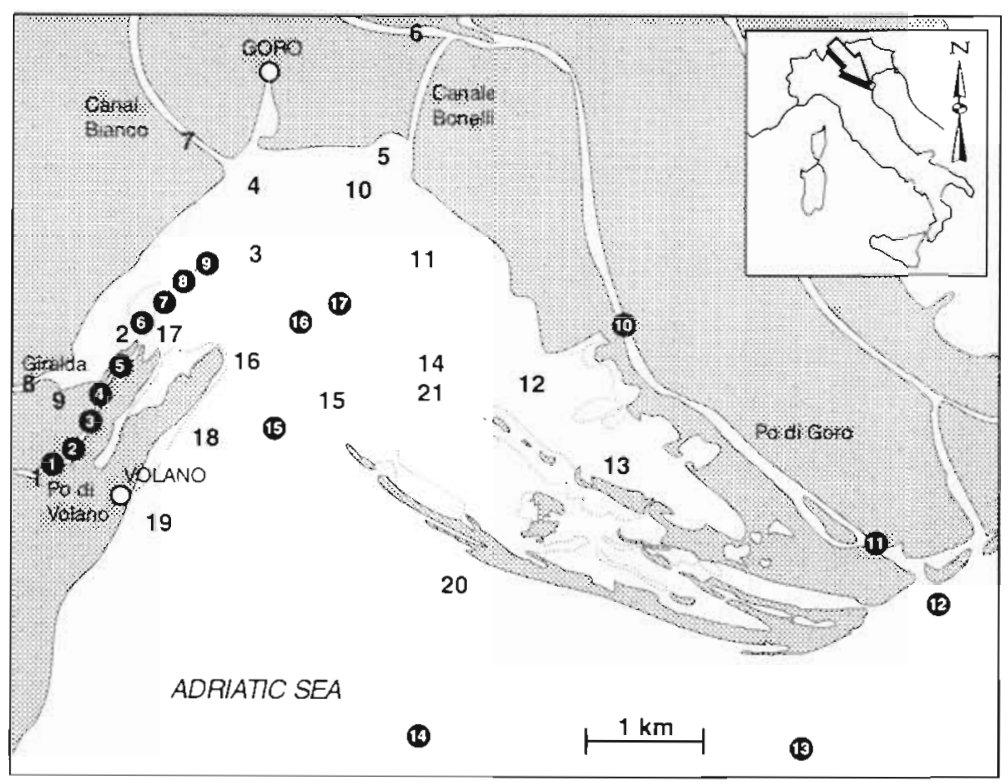

Fig. 1 Sacca di Goro, an open lagoon in the deltaic system of the Po river Numbers indicate the distribution of the sampling stations of 8 and 9 June and 17 October (in black circles) 1990

selectivity and the sensitivity of the measurements. The spectrofluorimeter used was a Perkin Elmer MPF66 operated at high gain and in the ratio mode. The spectra were not corrected for the instrumental response. The spectra were first adjusted for the superimposed effect of absorption of exciting radiation and selfabsorption of emitted radiation. This method has been extensively described by Ferrari \& Tassan (1991) using the correction factor $f$ suggested by Duursma \& Rommets (1961):

$$
f=\frac{\mathrm{e}^{-A_{y}\left(\lambda_{e}\right) S}-1}{A_{y}\left(\lambda_{e}\right) S} \times \frac{\mathrm{e}^{-A_{y}\left(\lambda_{1}\right) s}-1}{A_{y}\left(\lambda_{1}\right) S}
$$

where $A_{y}(\lambda)$ is the DOM absorption coefficient at wavelength $\lambda\left(\mathrm{m}^{-1}\right), s$ is the sample dimension $(\mathrm{m})$, and $\lambda_{\mathrm{e}}$ and $\lambda_{i}$ are the wavelengths of the exciting and induced radiation. When using a $\Delta \lambda=$ $25 \mathrm{~nm}$, the Raman scattering signal of the solvent (water) interferes with the first peak of the DOM sample at an excitation wavelength of $276 \mathrm{~nm}$. All spectra

ini et al. (1995). Samples taken from few-day to manymonth-old cultures were filtered through Millipore $0.22 \mu \mathrm{m}$ pore size membrane and analysed by fluorescence. Benthic macroalgae Ulva rigida, Gracilaria verrucosa and Cladophora lehmanniana were collected along with water from the Sacca di Goro and stored in white PVC bottles at room temperature. As for the diatoms, filtrate samples were taken at intervals and analysed. Phytoplankton and benthic algae were chosen as representing the dense algal populations of lagoons such as Sacca di Goro, where their decomposition frequently gives rise to anoxic phenomena.

Synchronous fluorescence spectroscopy. Synchronous fluorescence spectroscopy is an instrumental technique involving the simultaneous scanning of the excitation and emission monochromators, keeping a constant wavelength or energy offset between the monochromators (Lloyd 1971, Vo-Dinh 1978, Inman \& Winefordner 1982). This technique allows a better resolution of individual fluorescent components of DOM through a narrowing of the emission band spectra of a single fluorescent structure. The spectral resolution is higher when the wavelength differences between the excitation and the emission bands are small. However, when the monochromators offset is small, the signal strengths are low; consequently, for multicomponent mixtures of natural DOM samples, a wavelength offset of $\Delta \lambda=25 \mu \mathrm{m}$ has been chosen on the basis of experience and suggestions from the literature (Vo-Dinh 1978). This represents a trade-off between the spectral were blank-subtracted using Milli-Q water spectrum. To minimise the error arising from drift of the instrumental response, the Raman scattering spectrum of Milli-Q water was produced in succession with the DOM measurement. However, a small variability of the Raman height peak of Milli-Q water has been found (only \pm 0.5 to $1 \%$ for a series of 10 consecutive determinations).

Absorption and fluorescence emission measurements. Absorption and emission fluorescence measurements were performed on all samples in order to obtain a quantitative evaluation of the DOM. The absorption measurements were performed with a Perkin Elmer Lambda-array 3840 spectophotometer using a $10 \mathrm{~cm}$ long quartz cell and Milli-Q water as a blank. Emission fluorescence was measured using a Perkin Elmer MPF66 fluorometer. Further details on these methodologies can be found in Ferrari \& Tassan (1991).

DOC measurements. In order to assess the correlation between the absorption and emission fluorescence and DOC concentration, a subset of 17 samples, collected in October 1990 (see Fig. 1), was analysed for DOC. The samples were filtered on Millipore $0.22 \mu \mathrm{m}$ pore size membrane, fixed with $\mathrm{NaN}_{3}$, and analysed within 1 mo after the collection. The measurements were performed using a Carlo Erba-Fisons TCM 480 analyser which implies a high temperature oxidation reactor thermoregulated at $1020^{\circ} \mathrm{C}$ (ceramic column with $\mathrm{NiO}$ and nitrogen as carrier gas). The inorganic carbon was stripped with 
$0.5 \% \mathrm{HCl}$ solution and nitrogen to separate carbon dioxide from the sample. The reduction was performed at $400^{\circ} \mathrm{C}$ using hydrogen as reducting carrier gas (glass column with $\mathrm{Cu}$ and $\mathrm{Ni}$ as catalysts). The resulting methane was measured with a Flame Ionisation Detector (FID). whose signal is fed to a potentiometric chart recorder and is directely proportional to the amount of organic carbon present in the original sample. The relative instrumental counts were calibrated with a linear calibration curve obtained using samples of potassium biphthalate (mother solution, in Milli-Q water, of $5.3 \mathrm{mg} \mathrm{l}^{-1}$ ) as standard in a range from 5 to $50 \mathrm{ppm}$. The blank was performed with Milli-Q water and was found invariant with time and equal to $1.04 \mathrm{ppm}$ [standard deviation $(\mathrm{SD})=0.076$ on 39 observations]. The final data were the results of an average of a minimum of 4 determinations. The error of determination was estimated as $\pm 1.95 \%$ with $95 \%$ confidence limits of 0 and $\pm 5.2 \%$. The estimate has been derived on a population of 91 averages each formed by 4 replicates.

\section{RESULTS AND DISCUSSION}

Eq. (1) was applied to derive the correction factors for the inner filter effect on the synchronous fluorescence spectra. Depression factors, calculated on filtered samples from different algal cultures, are shown in Fig. 2, and the difference between the DOM spectra before and after correction are represented in Fig. 3 for Ulva rigida. The results indicate that correction is not negligible for samples with high DOM concentration and thus high absorption.

Synchronous fluorescence spectra obtained from the analysis of DOM produced by the algal cultures are represented in Fig. 4. The spectrum of DOM from all

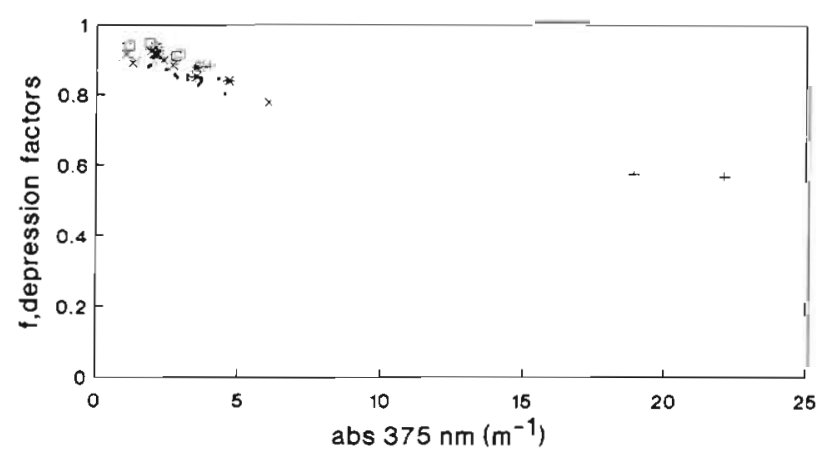

Fig. 2. Depression factors for algal culture filtrates computed using Eq. (1) for $1 \mathrm{~cm}$ path-way sample excited at $276 \mathrm{~nm}$ radiation with emission fluorescence light at $301 \mathrm{~nm}$ for algal culture filtrates at different absorption (abs) coefficients. (-) Skeletonema costatum; ( $\square$ ) Gracilaria verrucosa; (+) Ulva rigida; $(\times)$ Phaedactylum tricornutum; $(*)$ Cladophora lehmaniana algal species exhibits 3 main peaks having different height ratios between them: the first, hA, with an excitation wavelength of 270 to $277 \mathrm{~nm}$; the second, $\mathrm{hB}$, of 342 to $350 \mathrm{~nm}$; and the third, hC, of 385 to $390 \mathrm{~nm}$. Additional 'shoulders' were noted for the oldest cultures: at $420 \mathrm{~nm}$ for Skeletonema costatum, at $430 \mathrm{~nm}$ for Nitzschia closterium, and at $470 \mathrm{~nm}$ for Phaeodactylum tricornutum. Different spectral configurations were observed among species as well as according to the degree of ageing of the same species. According to Gordon et al. (1976), the peak position is due to the complexity of the aromatic structure of the DOM. In general, the first peak is ascribed to fluorophores with 1 aromatic ring which have aliphatic, alcoholic or ester bonds but which do not have further substitutions which could shift the synchronous peaks towards longer wavelengths (Patterson et al. 1984). Gordon et al. (1976) attribute fluorescence peaks polyaromatic rings systems to higher wavelengths. In addition, particular functional groups substituted on a monoaromatic structure result in a shift of the emission peak. For example, in contrast to benzene (excitation peak at $270 \mathrm{~nm}$ ), sodium salicylate exhibits a peak at $320 \mathrm{~nm}$ (Berlman 1965). Fig. 5 shows synchronous spectra $(\Delta \lambda=25 \mathrm{~nm})$ of compounds involved in almost all biological processes and that have been found in many aquatic environments. Monoaromatic compounds and tryptophan peaks are located between 270 and $300 \mathrm{~nm}, 2$ condensed ring systems between 310 and $370 \mathrm{~nm}$, fulvic acid between 370 and $400 \mathrm{~nm}$ and humic acids and other compounds at $470 \mathrm{~nm}$ and more. In natural waters, further complications can derive from $\mathrm{pH}$ variations and from the presence of metals, such as iron and copper, which induce spectral changes in the fluorescence (Cabaniss \& Shuman 1987).

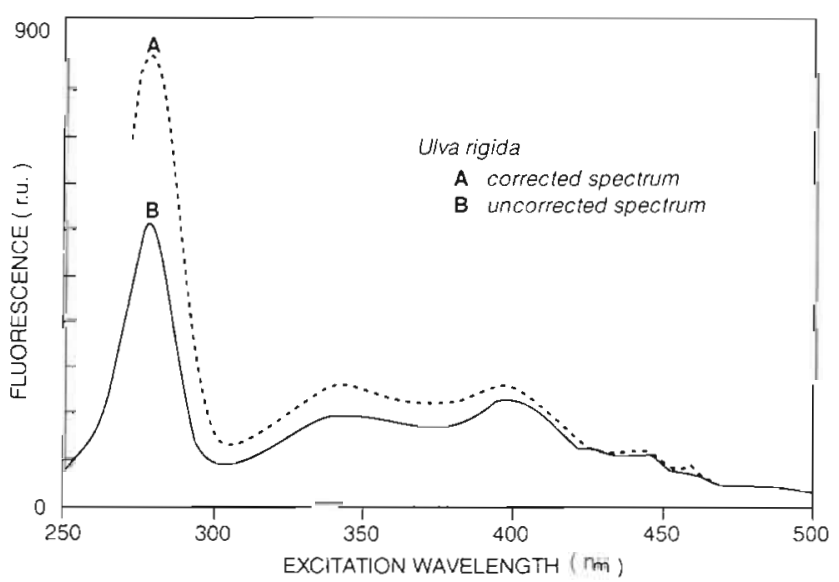

Fig. 3. Ulva rigida. Synchronous excitation-emission spectra $(\Delta \lambda=25 \mathrm{~nm})$ after $14 \mathrm{~d}$ storage in a plastic bottle. A: after absorption and Raman corrections. B: before absorption and Raman corrections. Fluorescence in relative units 

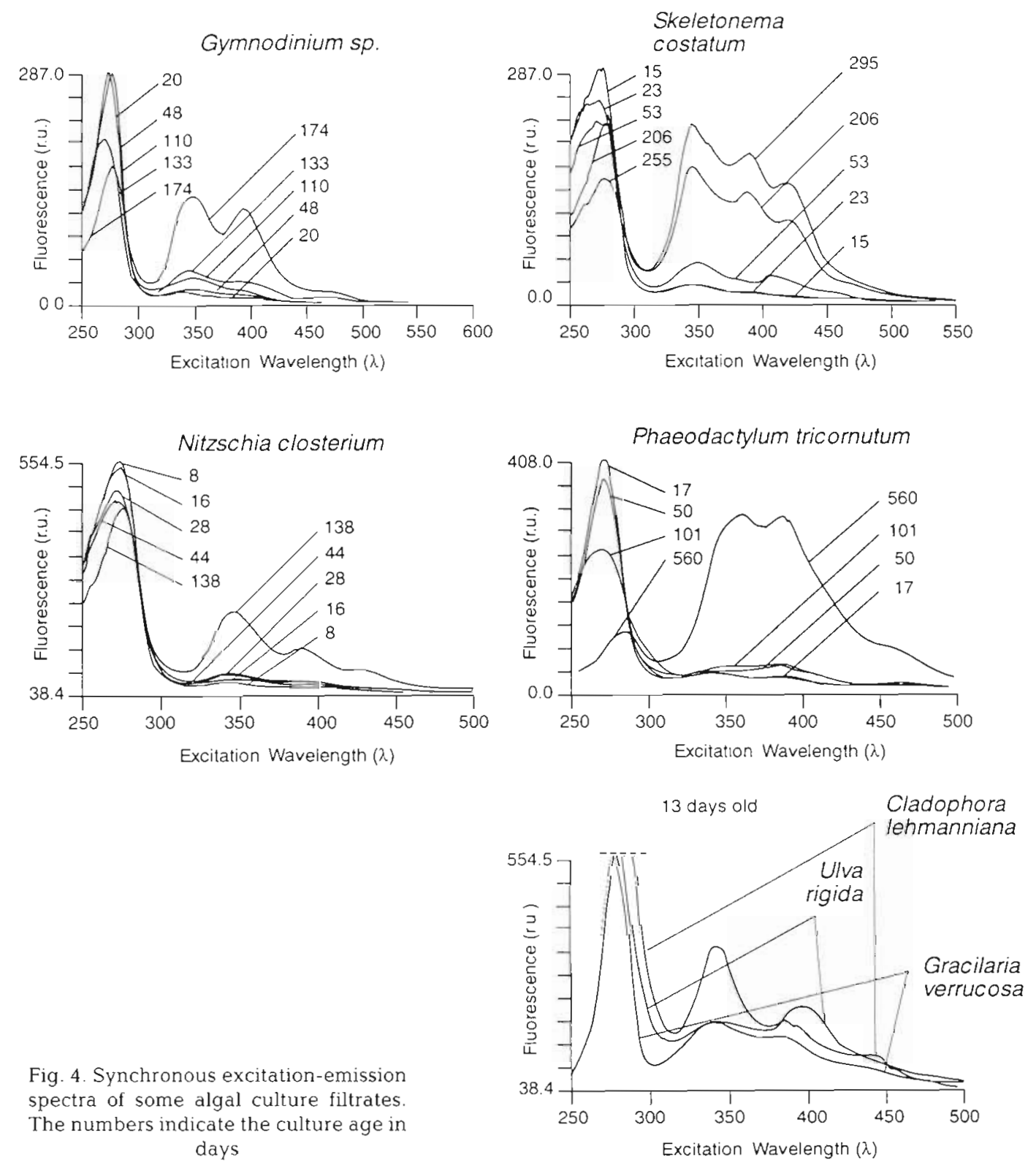

These results are similar to those reported by Gordon et al. (1976), who, working on crude oil in surface water, found in their synchronous spectra a range of 270 to $300 \mathrm{~nm}$ for the first peak (1-ringed aromatics) and 310 to $340 \mathrm{~nm}$ for the second peak (2-ringed aromatics). Note that the Gordon et al. (1976) ranges are expressed as emission wavelength, while, in our study, ranges are expressed as excitation wavelength; consequently, in order to make comparisons, $25 \mathrm{~nm}$ have to be added to our range.

On the basis of the spectral bands of Fig. 5, the hA peak of algal cultures (Fig. 4) could be related to the presence of amino acids like tyrosine or to monoaro-

matic phenolic compounds, precursors of part of the future fluorescent DOM, as reported by Sieburt \& Jensen (1969). Myklestad et al (1989) found that fluorescent extracellular amino acids like tyrosine and phenylalanine are released during the stationary phase of Chaetoceros affinis cultures. However, Traganza (1969) found fluorescent spectra similar to those of tyrosine when analysing extracellular DOM from Skeletonema costatum growing cultures.

Although, on the one hand, there are still uncertainties about the chemical structure, on the other hand, a different temporal trend of the compounds fluorescing at the different spectral bands of the DOM from algal 


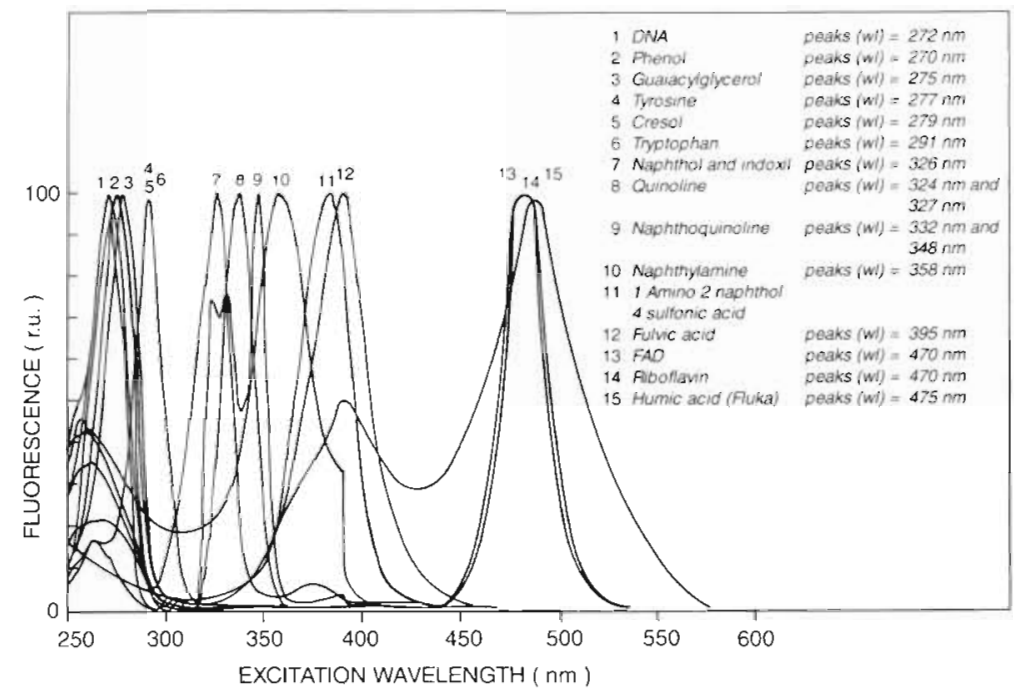

Fig. 5. Synchronous spectra $(\Delta \lambda=25 \mathrm{~nm})$ of various compounds present in natural dissolved organic matter. Spectra are not to scale
hB:hC values do not exhibit a time-dependent trend. A decrease in the hA:hB ratio over time may be evidence of the progressive accumulation of fluorescent compounds which are different from those fluorescing in the A band and which prevail in the medium of more aged cultures (Fig. 4).

Fig. 7 shows synchronous spectra of the samples collected in situ in Sacca di Goro (Fig. $7 \mathrm{~A}$ ) and in the rivers $\mathrm{Po}$, Adige and Brenta (Fig. 7B) in June and October 1990 and June 1991. The spectra exhibit 3 main peaks at 270 to $277 \mathrm{~nm}$, at 342 to $350 \mathrm{~nm}$, and at 385 to $390 \mathrm{~nm}$. The bands are similar to those (hA, hB and hC) of the algal cultures spectra. An additional peak at $310 \mathrm{~nm}$, found in the Brenta river mouth, indicates possible contamination. Good correlations, with linear fit, between absorption at $375 \mathrm{~nm}$ cultures is evident. In fact, the results shown in Fig. 4 highlight a progressive decrease of the first peak with a corresponding rise of the second and the third peaks in relation to the increasing age of the cultures. Thus, while the first peak prevails in all young cultures, the other synchronous peaks are higher in the oldest. The decrease of hA may be due to a cellular reabsorption phenomenon such as in the case of amino acids which are reabsorbed during growth (Fogg 1966) or to a chemical transformation with synthesis of new products, as proposed by other authors (Ehrhardt 1984). This spectral behaviour was described calculating the peak height ratios $h \mathrm{~A}: \mathrm{hB}$ and $\mathrm{hB}: \mathrm{hC}$ on a growing culture of Skeletonema costatum, as shown in Fig. 6. The peak height ratio $\mathrm{hA}: \mathrm{hB}$ is high during the logarithmic phase and decreases progressively over time, while the

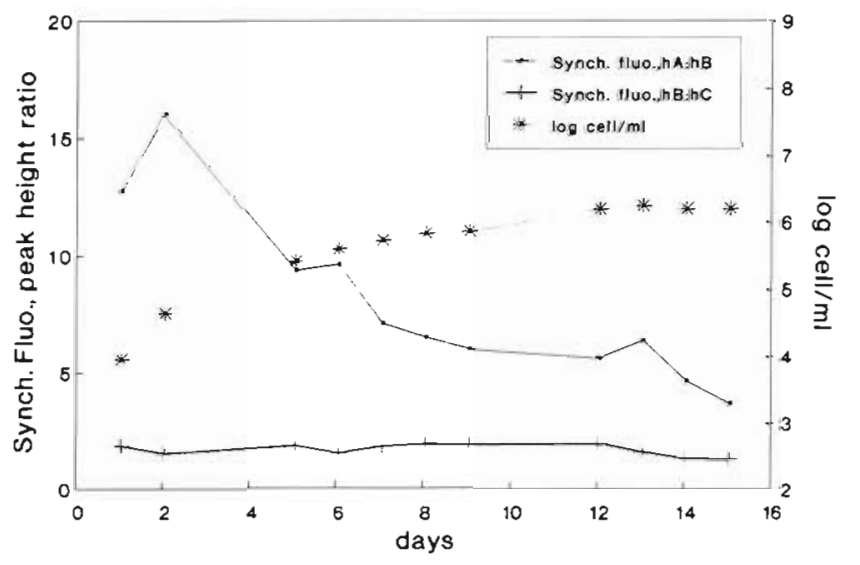

Fig. 6. Skeletonema costatum. Representation of the trend of the corrected hA:hB and hB:hC peak height ratios and cell concentration versus time during the growing test with the synchronous peak height at $344 \mathrm{~nm}(\mathrm{hB})[\mathrm{r}=$ $0.99, A$ (intercept) $=-0.153 \pm 0.027, B$ (slope) $=0.216 \pm$ $0.005, N$ (no. of observations) $=21$ J as well as with the emission peak height at $420 \mathrm{~nm}$ (excitation wavelength $=308 \mathrm{~nm})(\mathrm{r}=0.99, A=-0.88 \pm 0.11, B=1.04$ $\pm 0.023, N=21$ ) have been found for the study site samples (Fig. 8A). In addition, a good correlation between absorption $(r=0.88, A=-3.7 \pm 1.55, B=$ $0.35 \pm 0.05, N=17)$ and emission fluorescence $(\mathrm{r}=$ 0.89. $A=-20.99 \pm 6.6, B=1.58 \pm 0.21, \mathrm{~N}=17$ ) and all the DOC values has been found (Fig. 9). In our case DOC values are 5 to 10 times higher than these reported in the literature for coastal waters (Sugimura \& Suzuki 1988, Bocastow \& Maier-Reimer 1991, Tanoue 1992, Sharp et al. 1993). This may be due both to the analytical method of high temperature catalytic oxidation used (Wangersky 1993) and to the peculiar condition of the test site, which was characterised by very high DOM content. The good correlation found can be taken as evidence of how the optical parameters of DOM (absorption and fluorescence) are effective for the estimation of the amount of DOC present (Fig. 9). Fig. 9 indicates high specific fluorescence (for DOC units) with respect to absorption, probably due to substances transported by the Giralda channel when this joins with the Po di Volano into the Sacca di Goro (Stns 6, 7, 8, in Fig 1)

In contrast, the marine Stns 13 and 14 are characterised by low specific fluorescence while the Stn 15 , at the entrance of the lagoon, shows low specific values both for fluorescence and absorption, probably because of substances mobilised from the bottom by the passage of fishing boats. Given this particular data set (high values and no data $<10 \mathrm{ppm}$. of DOC), it 

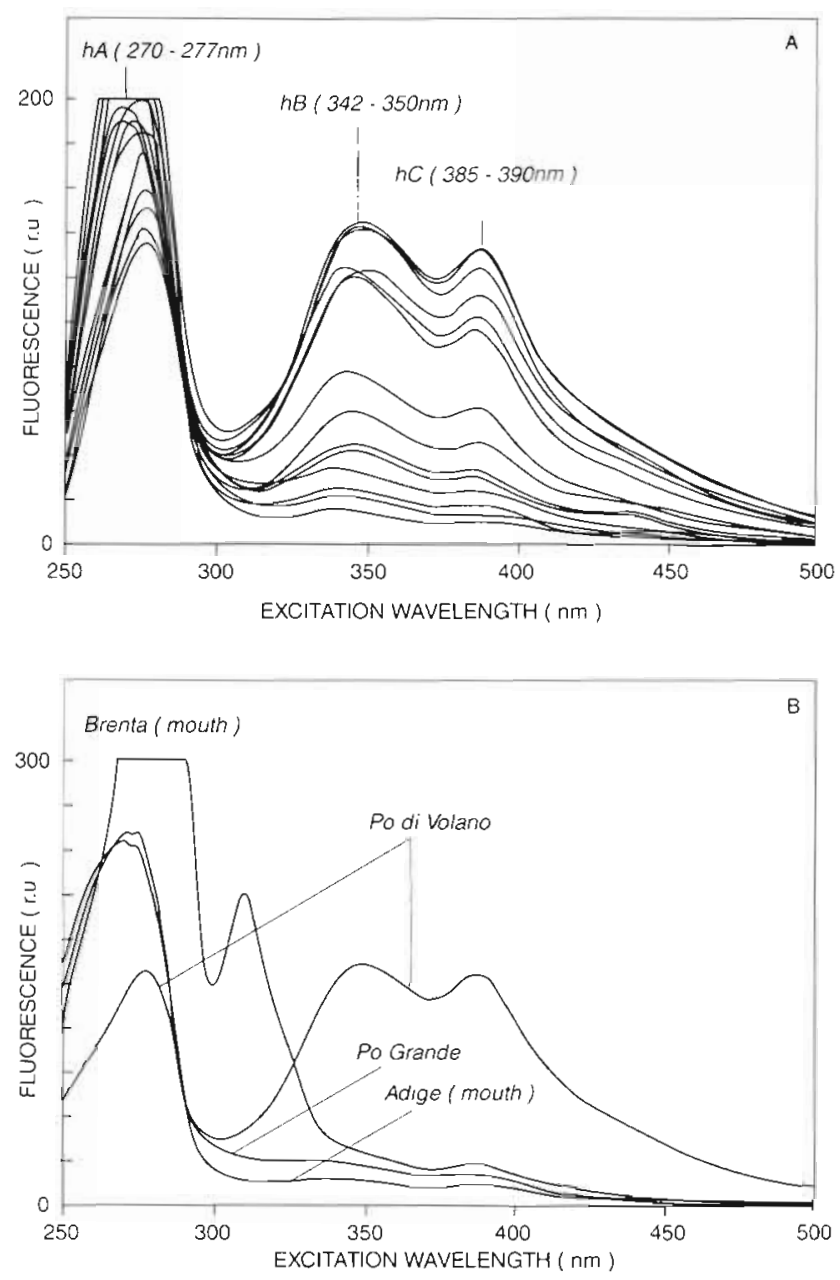

Fig. 7 Synchronous spectra with the main peaks of the samples collected $(A)$ in the Sacca di Goro and $(B)$ in the rivers of the Po delta system. Note, for the Brenta river, the peak at $310 \mathrm{~nm}$ which indicates possible contamination

is not possible to derive a general expression from the obtained best fits. It should be noted, however, that absorption, with respect to fluorescence, predicts DOC more correctly because, as shown in Fig. $8 \mathrm{~A}$ where the best fit line does not match the point $(0,0)$, not all the light energy absorbed is remitted as fluorescence. According to Stewart \& Wetzel (1981), this may be due to internal quenching and shielding in compounds of large molecular weight or to energy transfer within the molecules (Donald et al. 1987). The correlation, with linear fit, has been found to be Iow ( $\mathrm{r}=0.77, A=0.75 \pm 0.55, B=0.65 \pm 0.17, \mathrm{~N}=12$ ) for Skeletonema costatum, while the macroalgae Cladophora lehmanniana and Ulva rigida show a different distribution of the points in the graph (Fig. 8B). While $\mathrm{hB}$ correlates well with absorption, the synchronous peak in the UV region (hA) does not correlate with any other parameter. This can be due to the presence
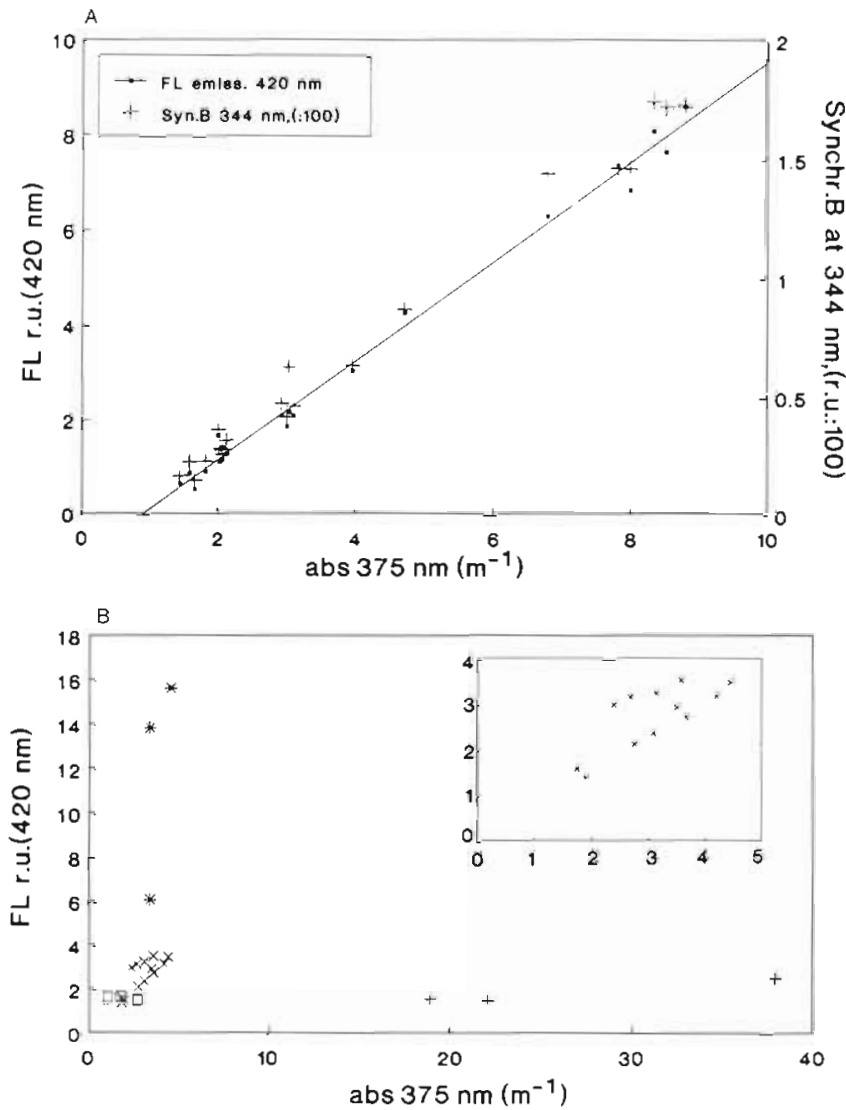

Fig. 8. (A) Plot of the absorption (375 nm) versus fluorescence expressed as peak height emission at $420 \mathrm{~nm}$, normalised on the Raman peak height of Milli-Q water, and as synchronous peak height at $344 \mathrm{~nm}$ for the Sacca di Goro in June 1990. In both cases the correlation is $r=0.99$. (B) Plot of the absorption $(375 \mathrm{~nm})$ versus normalised fluorescence emission at $420 \mathrm{~nm}$ for algal cultures filtrates. ( $\times$ ) Skeletonema costatum; $(+)$ Ulva rigida; (*) Cladophora lehmanniana; () Gracilaria verrucosa. Note the high quantum yield of $C$. lehmanniana and the low quantum yield of $U$. rigida. Inset: plot of the absorption $(375 \mathrm{~nm})$ versus fluorescence emission at $420 \mathrm{~nm}$ for $S$. costatum culture filtrates $\{r=0.77)$

of high quantum yield fluorescent substances at low concentrations which are basically not dependent on the total absorption coefficient at $375 \mathrm{~nm}$. For example, trace levels of tyrosine are able to produce a high synchronous fluorescence peak in the UV region.

A comparison between the spectral characteristics of algal-cultured DOM with those of natural samples from the Sacca di Goro and other rivers of the Po delta has shown that the fluorescence configurations of the Po di Volano and of other input channels are apparently similar to those of the algal-cultured DOM. The spectral features of DOM of the Po di Volano and of the channels can be ascribed (in addition to the prevalent algal processes) to compounds derived from terrestrial plant degradation which 
Table 1. Averaged ratios, with relative standard deviations in parentheses, between chlorophyll concentrations (mg $\mathrm{m}^{-3}$ ), obtained via SCOR Unesco method (Strickland \& Parsons 1972), and absorption coefficient at $375 \mathrm{~nm}$ in Sacca di Goro and in some rivers and channels of the Po river delta

\begin{tabular}{|llllccccc}
\hline Date & $\begin{array}{c}\text { Sacca } \\
\text { di Goro }\end{array}$ & $\begin{array}{c}\text { Podi } \\
\text { Volano }\end{array}$ & $\begin{array}{c}\text { Podi } \\
\text { Goro }\end{array}$ & $\begin{array}{c}\text { Bonelli } \\
\text { Channel }\end{array}$ & $\begin{array}{c}\text { Bianco } \\
\text { Channel }\end{array}$ & $\begin{array}{c}\text { Giralda } \\
\text { Channel }\end{array}$ & Adige & Brenta \\
\hline 5-8 Jun 1990 & $1.54(1.13)$ & 3.7 & 11.5 & 34.36 & 5.8 & 18.4 & - \\
2-3 Oct 1990 & 2.04 & $0.87(0.22)$ & $1.33(0.36)$ & - & - & - & 2.33 & 11.3 \\
10-11 Jun 1991 & $1.38(1.21)$ & 1.3 & 4.34 & - & - & - & 0.92 \\
\hline
\end{tabular}

involves the lignin through the photooxidation of the guaiacilglycerol, a precursor of successive DOM compounds (Larson \& Rockwell 1980, Vodacek 1992). The hypothesis that DOM has an algal origin can be proposed for the Bonelli and Giralda channels (see Fig. 1), where the chlorophyll:DOM ratio is about 10 times higher than that found in the Sacca di Goro and in the Po di Volano as shown in Table 1. In the Sacca di Goro, synchronous fluorescence spectra do not allow us to distinguish DOM transported by the Po di Volano from that produced inside the lagoon by algal exudation or decomposition. Among the spectra shown in Fig. $7 \mathrm{~A}$, those with higher peaks hA and $\mathrm{hB}$ are from the samples collected at the entrance of the Po di Volano and other channels, while the configurations of the other spectra cannot be explicitly ascribed to the inland input nor to some particular algal groups as shown in Fig. 4.

At this point, the question remains: how can DOM formed in situ be distinguished from that produced and transported by the rivers? Probably the approach needed to solve the problem requires a model of general circulation and must assume as a conservative parameter the DOM entering the lagoon. However, the results permit us to estimate the degree of mixing

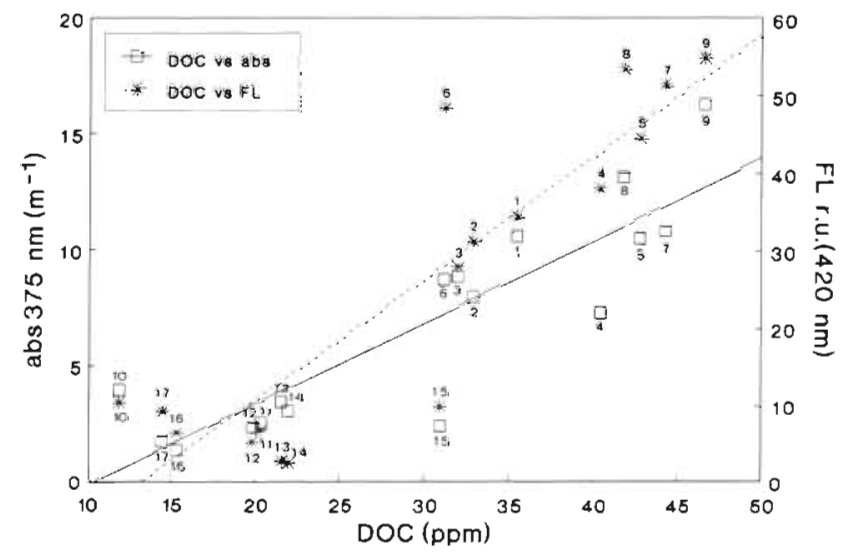

Fig. 9. Plot of dissolved organic carbon (DOC, in ppm) versus absorption (abs) (375 nm) and fluorescence emission peak at $420 \mathrm{~nm}$ (excitation at $308 \mathrm{~nm}$ ). Set of samples collected on 17 October 1990. Numbers indicate the stations shown in Fig. 1 with DOM of marine origin and provide us with a technique for a timely monitoring of unexpected industrial or urban inputs such as, for example, that of tryptophan and its derivative indoxil, which are produced by bacterial activity (Dalterio et al. 1986). The synchronous spectrum with a peak at $309 \mathrm{~nm}$ of the water at the embouchment of the Brenta river can be taken as an example in this respect (Fig. 7B).

Based on the fluorescence peak height ratio hA:hB plotted against the absorption coefficient at $375 \mathrm{~nm}$, some interesting results can be derived regarding the DOM fluorescence distribution in the Sacca di Goro with respect to that of its tributaries and of the open sea (Fig. 10). The variability of the hA:hB ratio is very high for the samples gathered inside the lagoon. The maximum values were found for the marine stations most distant from freshwater inputs, while the lower values were found in the Po di Volano and in the channels as well as in the stations close to their input into the lagoon. The quasi-constant ratio $h A: h B$ versus the variation of the absorption can be indicative of a similar DOM composition in these latter zones. The spectral ratio $h A: h B$, with respect to absorption, may be a more effective tracer of the fluvial organic constituents in coastal and deltaic systems. Fig. 11 shows the mix-

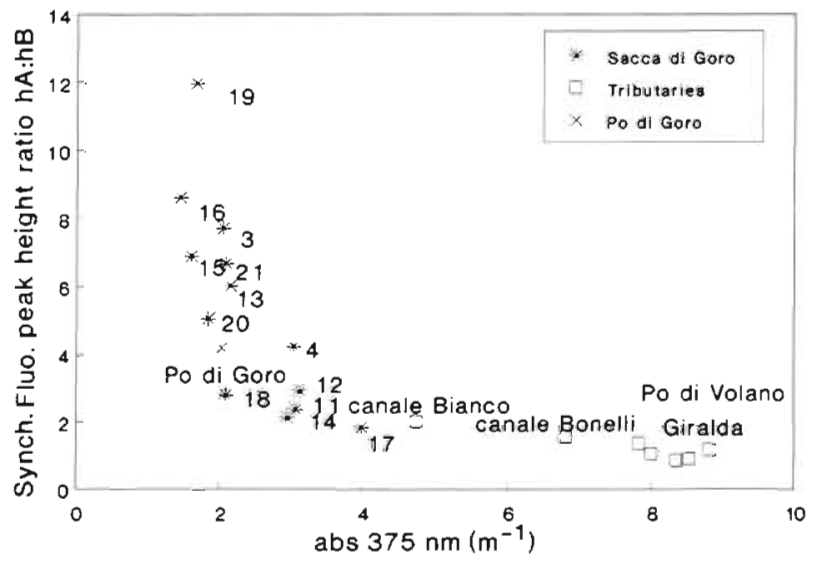

Fig. 10. Plot of synchronous hA:hB peak helght ratio versus the absorption (375 nm) for the samples of Sacca di Goro and its tributaries (June 1990) 


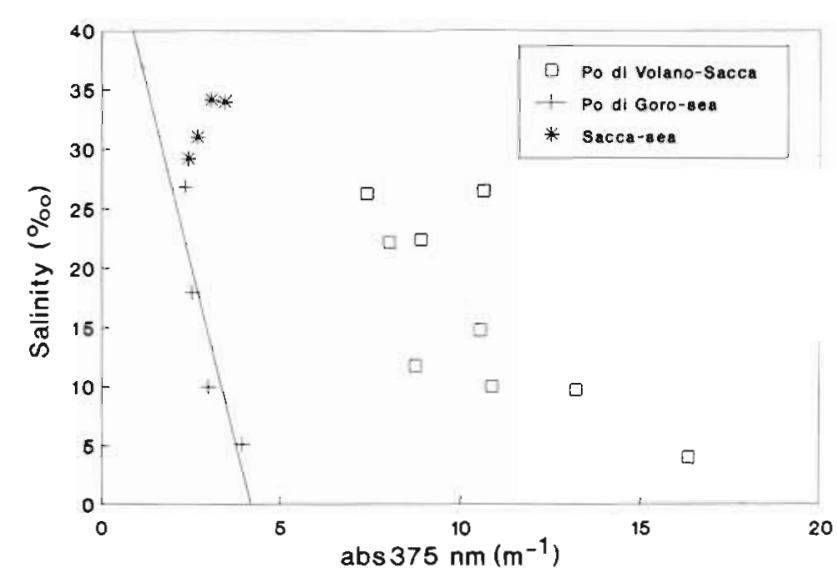

Fig. 11. Mixing curves (absorption versus salinity) of the fluvial waters and of the interface zones: Po di Volano, Sacca di Goro, Po di Goro open sea and Sacca di Goro open sea. Measurements performed ad hoc in October 1990

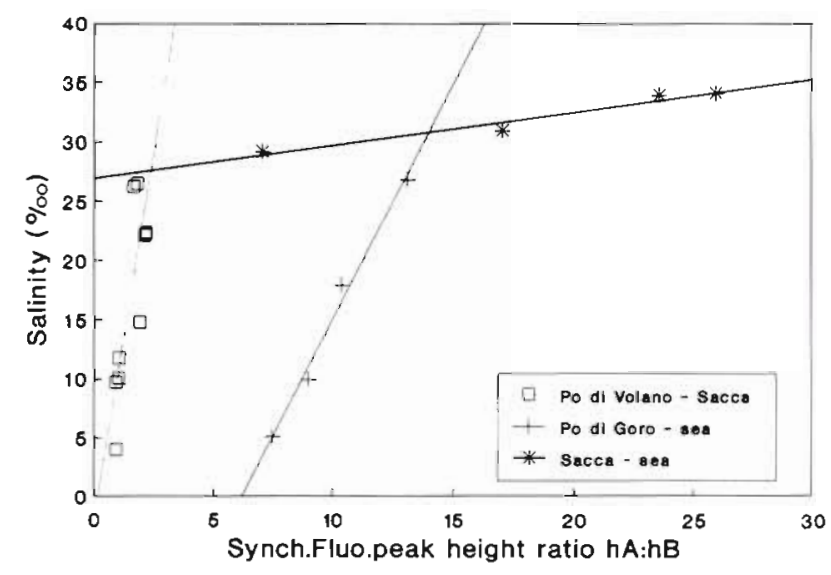

Fig. 12. Mixing curves, represented as synchronous hA:hB peak height ratio versus salinity, for the same zones cited in Fig. 11

ing curves (absorption versus salinity) of the Po di Volano and the Po di Goro rivers with marine waters obtained during a series of measurements made in October 1990. Fig. 12 shows the mixing curves obtained using $h A: h B$ as a tracing parameter for the systems: Po di Volano, Sacca di Goro, Sacca di Goro sea and Po di Goro sea. The curves are fitted as straight lines. For the Po di Volano, for which more values have been compared, the correlation between salinity and fluorescence is better than that found between salinity and absorption $(r=0.93, A=-2.32 \pm$ $2.36, B=11.1 \pm 1.3$ and $r=0.75, A=39.56 \pm 7.83, B=$ $-2.2 \pm 0.72$, respectively). Actually the fluorescence parameter hA/hB, with respect to absorption, is much more sensitive to the small variations of the salinity in the Po di Goro sea and especially in the Sacca di Goro sea systems.

\section{CONCLUSIONS}

Synchronous fluorescence spectroscopy allowed to characterise the DOM present in the Goro lagoon, distinguishing the different spectral components of the natural mixture. While the terrestrial contribution of organic substance was very high, as indicated by the DOC concentrations in the channels samples, the DOM components both from fresh and seawater samples were not basically different from a qualitative point of view. However, a spectral difference can be found, based on the intensity ratio of the DOM components fluorescing with the synchronous peak at $\lambda=275 \mathrm{~nm}$ (band hA), with respect to those with synchronous peaks at $\lambda>300 \mathrm{~nm}$ (bands $\mathrm{hB}$ and $\mathrm{hC}$ ). While the spectral band hA generally prevailed in the seawater samples, the intensity of the $h B$ and hC bands was higher in the channels. On the basis of our results, the synchronous peak height ratio hA:hB seems a useful parameter for describing the different contributions of the Goro lagoon DOM and the degree of mixing with inland DOM, coming from the channels, with that produced in marine waters.

More information on the nature of DOM is provided by the results obtained by means of marine algal assays. The spectral bands of the fluorescent DOM produced by the algal cultures were not different from those found in natural water samples, from both terrestrial origin (channels) or generated in the lagoon. Our results allowed us to distinguish 2 categories of components, mainly differentiated on the basis of the production trend by algal cultures over time. DOM with a synchronous peak hA is produced by algae in the condition of active growth, as exhibited by the Skeletonema costatum growth test. These fluorescent DOM components, which were observed in all cultured algal species, clearly prevail in young cultures. A second group of compounds was identified by the synchronous bands $\mathrm{hB}$ and $\mathrm{hC}$. These organic substances are produced continuously, in various mixtures, and accumulated in the culture medium over time, even in senescent phases, which thus prevail in most aged cultures. The synchronous peak height ratio $\mathrm{h} A: \mathrm{hB}$ can be effective, in this case as well, in reflecting the degree of ageing of DOM production by phytoplankton in seawater.

The results of this study seem to confirm the diagnostic capability of the synchronous spectra fluorescence technique applied to the study of sources, circulation and mixing of DOM in marine deltaic systems. Combined studies, addressing the chemical composition of DOM and using high performance liquid chromatography to separate the individual DOM components, would be useful in order to obtain a databank of natural fluorescent model substances as an aid in understanding the nature of the compounds which produce the synchronous spectra. 
Acknowledgements. The authors thank the 'Assessorato Ambiente' of the Amministrazione Provinciale di Ferrara, which provided the RV 'Hydra', the staff of which was very helpful during the water sampling in Sacca di Goro. The manuscript also benefitted from comments of 2 anonymous reviewers and from the useful suggestions of Dr Anthony Vodacek of the University of Maryland.

\section{LITERATURE CITED}

Berlman IB (1965) Handbook of fluorescence spectra of aromatic molecules. Academic Press, New York, p 1-258

Bocastow R, Maier-Reimer E (1991) Dissolved organic carbon in modeling oceanic new production. Global Biogeochem Cycles 5 (1):71-85

Cabaniss SE, Shuman MS (1987) Synchronous fluorescence spectra of natural waters: tracing sources of dissolved organic matter. Mar Chem 21:37-50

Cauwet G (1978) Organic chemistry of seawater particulates. Concepts and developments. Oceanol Acta 1 (1):99-105

Coble PG, Green SA, Blough NV, Gagosian RB (1990) Characterization of dissolved organic matter in Black Sea by fluorescence spectroscopy. Nature 348: 432-435

Coble PG, Schultz CA, Mopper K (1993) Fluorescence contouring analysis of DOC Intercalibration Experiment samples: a comparison of techniques. Mar Chem 41:173-178

Dalterio RA, Nelson WH, Britt D, Sperry J Psaras D, Tanguay JF, Suib SL (1986) Steady-state and decay characteristics of protein tryptophan fluorescence from bacteria. Appl Spectroscopy 40(1):86-90

Donard OFX, Belin C, Ewald M (1987) Corrected fluorescence excitation spectra of fulvic acids. Comparision with the UV/visible absorption spectra. Sci Total Environ 62: $157-161$

Duursma EK (1974) The fluorescence of dissolved organic matter in the sea. In: Jerlov NG, Steemann Nielsen E (eds) Optical aspects of oceanography. Academic Press, London, New York p 237-256

Duursma EK, Rommets JW (1961) Interpretation mathématique de la fluorescence des eaux douces, saumatres et marines. Neth J Sea Res 1,(3):391-405

Ehrhardt M (1984) Marine Gelbstoff. The handbook of environmental chemistry. In: Hutzinger $O$ (ed) The natural environment and the biogeochemical cycles, Vol 1, Part C. Springer-Verlag, Berlin, p 63-77

Ferrari GM (ed) (1990) 'Napoli 88' data catalogue. Internal report to the Commission of European Communities, Joint Research Centre, Ispra (VA), Italy, S.P.I. 90.15

Ferrari GM, Tassan S (1991) On the accuracy of determining light absorption by 'yellow substance' through measurements of induced fluorescence. Limnol Oceanogr 36(4): $777-786$

Fogg GE (1966) The extracellular products of algae. Oceanogr mar biol A Rev 4:195-212

Fogg GE (1983) The ecological significance of extracellular products of phytoplankton photosynthesis. Botanica mar 26:3-14

Gordon DC Jr, Keizer PD, Hardstaff WR, Aldous DG (1976) Fate of crude oil spilled on seawaters contained in outdoor tanks. Environ Sci Technol 10:580-585

Guillard RRL, Wangersky PJ (1958) The production of extracellular carbohydrates by some marine flagellates. Limnol Oceanogr 3:449-454

Harvey GR, Boran DA, Chesal LA, Tokar JM (1983) The structure of marine fulvic and humic acids. Mar Chem 12: $119-132$
Hellebust JA (1974) Extracellular products. In: Steward ND (ed) Algal physiology and biochemistry. University of California Press, Berkeley, p 838-863

Inman EL Jr, Winefordner JR (1982) Constant energy synchronous fluorescence for analysis of polynuclear aromatic hydrocarbon mixtures. Analyt Chem 138:2018-2022

Jackson AG (1993) The importance of the DOC pool for primary production estimates. ICES mar Sci Symp 197: $141-148$

Jensen A (1984) Excretion of organic carbon as function of nutrient stress. In: Holm-Hansen O, Bolis L, Gilles R (eds) Lecture notes on coastal and estuarine studies, 8 . Marine phytoplankton and productivity. Springer Verlag, Berlin, p 61-72

Kalle K (1963) Über das Verhalten und die Herkunft der in den Gewässern und in der Atmosphäre vorhandenen himmelblauen Fluorezenz. Dt hydrogr Z 16:153-166

Larson RA, Rockwell AL (1980) Fluorescence spectra of water-soluble humic material and some potential precursors. Arch Hydrobiol 89:416-425

Lloyd JBF (1971) Synchronized excitation of fluorescence emission specta. Nature phys Sci 231:64-65

Marker AFH (1965) Extracellular carbohydrates liberation in the flagellate Isochrysis galbana and Prymnesium parvum. J mar biol Ass UK 45:755-772

Mingazzini M, Colombo S, Ferrari GM (1995) Application of spectrofluorimetric techniques to the study of mucilages in the Adriatic Sea: preliminary results. Sci total Environ 165: $133-144$

Momzikoff A (1969) Recherche sur les composés fluorescents de l'eau de mer. Identification de I'isoxanthopterine, riboflavine et du lumichrome. Cah Biol mar, 10:221-230

Mopper K, Degens ET (1979) Organic carbon in the ocean nature and cycling. In: Bolin B, Degens ET, Kempe S, Ketner P (eds) The global carbon cycle (Scope 13). John Wiley \& Sons, New York, p 293-315

Mopper K, Schultz CA (1993) Fluorescence as a possible tool for studying the nature and water column distribution of DOC components. Mar Chem 41:229-238

Mueller JL, Austin RW (1995) Ocean optics protocols for SeaWiFS validation, revision 1 . in SeaWiFS technical report series. NASA Tech Memo 25:7-12

Myklestad S, Holm-Hansen O, Varum KM, Volcani BE (1989) Rate of release of extracellular amino acids and carbohydrates from the marine diatom Chaetoceros affinis. J Plankton Res 11(4):763-773

Patterson HH, Huizenga D, Taylor T (1984) Kinetic study of the effects of acid rain on trace metal uptake. PB85215143, NTIS, Springfield, VA

Russo MC (1985) Evaluation of fluorescence spectroscopy as a method for measuring 'Gelbstoff' in aquatic environments. PhD thesis, University of London

Sharp JH, SuzukiY, MundayWL (1993) A comparision of dissolved organic carbon in North Atlantic Ocean nearshore waters by high temperature combustion and wet chemical oxidation. Mar Chem 41:253-259

Sieburth J, Jensen A (1969) Studies of algal substances in the sea, II. The formation of Gelbstoff (humic material) by exudates of phaeophyta. J exp mar Biol Ecol 3:275-289

Stewart AJ, Wetzel RG (1980) Fluorescence absorbance ratios. A molecular-weight tracer of dissolved organic matter. Limnol Oceanogr 25:559-564

Stewart AJ, Wetzel RG (1981.) Asymmetrical relationships between absorbance, fluorescence and dissolved organic carbon. Limnol Oceanogr 26:590-597

Strickland JD, Parsons TR (1972) A practical handbook of seawater analysis. Bull Fish Res Bd Can 167 
Sugimura Y, Suzuki Y (1988) A high temperature catalytic oxidation method for the determination of non-volatile dissolved organic carbon in seawater by direct injection of a liquid sample. Mar Chem 24:105-131

Tanoue E (1992) Vertical distribution of dissolved organic carbon in the North Pacific as determined by the high-temperature catalytic oxidation method. Earth Planet Sci Lett 111:201-216

Traganza ED (1969) Fluorescence excitation and emıssion

This article was submitted to the editor spectra of dissolved organic matter in seawater Bull mar Sci 19(4):899-904

Vodacek A (1992) An explanation of the spectral variation in fresh water DOM fluorescence. Limnol Oceanogr 37 . 1808-1813

Vo-Dinh T (1978) Multicomponent analysis of synchronous luminescence spectrometry. Analyt Chem 54:2018-2022

Wangersky PJ (1993) Dissolved organic carbon methods: a critical review. Mar Chem 41:61-74

Manuscript first received: April 22, 1994

Revised version accepted: March 27, 1995 